\title{
Synthesis and Magnetic Properties of Electrodeposited Cobalt-Iron-Vanadium Thin Films
}

\author{
Kwang Pyo Chae* \\ Department of Applied Physics, Konkuk University, Chungju, Chungbuk 380-701, Korea
}

(Received 14 March 2006)

\begin{abstract}
$\mathrm{CoFeV}$ thin film alloys were fabricated by electrodeposition, and the dependences of their magnetic properties on the current density were investigated using an $\mathrm{X}$-ray diffractometer and a vibrating sample magnetometer. The deposited Co increased from about 45 to 60 wt. \% with increasing current density until $25 \mathrm{~mA} / \mathrm{cm}^{2}$ whereas the deposited Fe decreased from about 55 to $40 \mathrm{wt}$.\% with increasing current density until $25 \mathrm{~mA} / \mathrm{cm}^{2}$. The deposited $\mathrm{V}$, about $2 \mathrm{wt} \%$, was independent of the current density. The current efficiencies of electrodeposition decreased linearly from about 40 to $29 \%$ with increasing current density. The X-ray diffraction measurement showed that all peaks of the CoFeV films were consistent with those of a typical Co hep and Fe bec mixed phase. An increase in the current density decreased the grain size and increased the lattice constant. The saturation magnetization increased from about 2.2 to $2.5 \mathrm{~T}$ with increasing current density. The coercivity measured in the perpendicular direction decreased from 260 to 120 Oe with increasing current density; a drastic drop of 60 Oe occurred at $5 \mathrm{~mA} / \mathrm{cm}^{2}$. The coercivity measured in the in-plane direction remained almost unchanged, at about 20 Oe, with increasing current density.
\end{abstract}

Key words : electrodeposition, thin film, current density, magnetic saturation, coercivity

\section{Introduction}

Magnetic films are interesting due to their many application in the magnetic industry, and they show various crystallographic and magnetic properties. Considerable interest has recently been focused on in the fabrication and the properties of nano-sized particles of magnetic materials [1-3]. The electrodeposition technique has been shown to be very convenient for thin films because of its simplicity of use and low cost $[4,5]$. One of the principle merits of the electrodeposition technique is that by varying the exact conditions of deposition, it is possible to fine tune the properties of the layer to suit specific requirements and to prepare ferromagnetic thin films, multilayers, and nanowires [6-8]. The electrodeposition technique can provide multicomponent compounds with homogeneous compositions, so it has been employed to prepare various magnetic materials. Recently, Lopez et al. [9] synthesized and characterized electrodeposited $\mathrm{Cu}_{90} \mathrm{Co}_{10}$ thin films. They showed that the as-deposited samples consisted of superparamagnetic clusters and diluted Co

*Corresponding author: Tel: +82-43-840-3623,

Fax: +82-43-851-4169, e-mail: kpchae@kku.ac.kr atoms. Upon annealing, greater superparamagnetic and ferromagnetic clusters appeared. Jones et al. [10] observed in electrodeposited $\mathrm{Co}_{\mathrm{x}} \mathrm{Re}_{100-\mathrm{x}}$ that the magnetic behavior was compatible with superparamagnetism in the crystalline phase at low Co concentrations whereas for higher Co concentrations, the alloys were ferromagnetic. Also, the effect of nitrogen content on the magnetic properties of Co-Ni-Mg-N thin films has been studied [11].

Although numerous studies have been carried out to investigate binary (CoFe, NiCo, NiFe) and ternary (CoNiFe) iron-group magnetic thin films, they mostly focused on the mechanism of anomalous codeposition, the effects of various additives, the effects of pulse plating, and the corrosion properties. To our knowledge, there have been a few detailed studies on $\mathrm{CoFeV}$ films prepared by using electrodeposition. The purpose of the present work was to study the effects of current density on the composition and on the crystallographic and the magnetic properties of electrodeposited $\mathrm{CoFeV}$ thin films. In this work, $\mathrm{CoFeV}$ films were electrodeposited at various current densities ranging from 3 to $50 \mathrm{~mA}$, and the crystallographic and magnetic properties were studied by means of x-ray diffractometer (XRD) and a vibrating sample magnetometer (VSM). We discuss the influence 
of the current density on the composition, structure, and magnetic properties of the films.

\section{Experimental}

Solutions were made using conventional methods [12, 13]. The effect of the current density on the composition of the deposited $\mathrm{CoFeV}$ film was investigated for current densities of $3,5,10,25$, and $50 \mathrm{~mA} / \mathrm{cm}^{2}$ at $\mathrm{pH}=7.00$, with constant current at room temperature. The $\mathrm{CoFeV}$ films were electrodeposited on brass substrates; $\mathrm{Fe}, \mathrm{Co}$, or V was used as the soluble anode.

The deposited $\mathrm{Co}, \mathrm{Fe}$, and $\mathrm{V}$ contents were determined using atomic absorption spectroscopy (AA), and the alloy compositions are given in weight percent. The magnetic properties, coercivity and magnetic saturation were determined using a vibrating sample magnetometer. The electrodeposited $\mathrm{CoFeV}$ films were etched using a solution of equal parts de-ionized water, $\mathrm{H}_{2} \mathrm{O}_{2}$, and $\mathrm{H}_{3} \mathrm{PO}_{4}$. An x-ray diffractometer with $\mathrm{Cu}-\mathrm{Ka}$ radiation was used to identify the phases.

\section{Results and Discussion}

Figure 1 shows the deposit $\mathrm{Co}, \mathrm{Fe}$, and $\mathrm{V}$ compositions and the current efficiency of electrodeposition as functions of the current density measured at room temperature. The Co content increased from about 45 to $60 \mathrm{wt} . \%$ with increasing current density until $25 \mathrm{~mA} / \mathrm{cm}^{2}$ whereas the Fe content decreased from about 55 to 40 wt. $\%$ with increasing current density until $25 \mathrm{~mA} / \mathrm{cm}^{2}$. The $\mathrm{V}$ content, at about 2 wt.\%, was independent of the current density. The current efficiencies of electrodeposition decreased linearly from about 40 to $29 \%$ with increasing

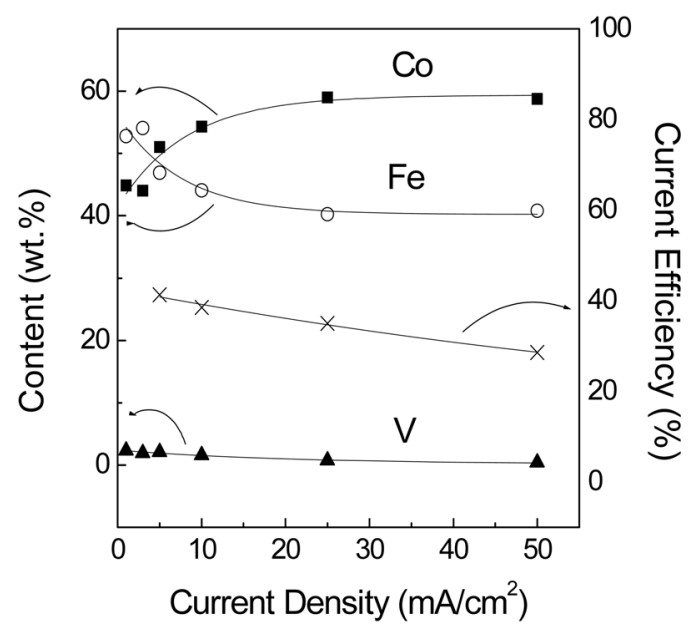

Fig. 1. Dependence of the composition and the current efficiency of $\mathrm{CoFeV}$ films on the current density.

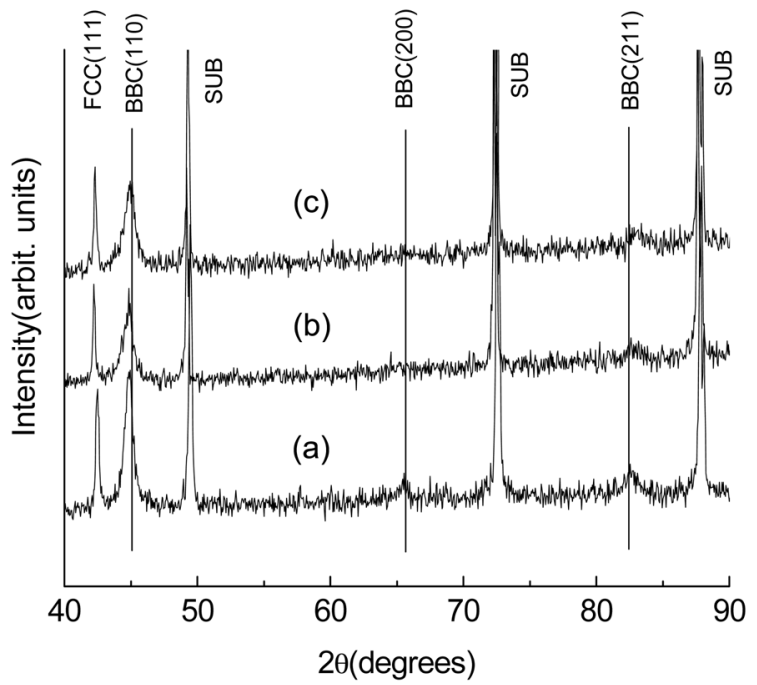

Fig. 2. X-ray diffraction patterns of $\mathrm{CoFeV}$ films at current densities of (a) $3 \mathrm{~mA} / \mathrm{cm}^{2}$, (b) $10 \mathrm{~mA} / \mathrm{cm}^{2}$, and (c) $50 \mathrm{~mA} / \mathrm{cm}^{2}$.

current density. Kim et al. [13] investigated the deposited $\mathrm{CoFe}$ alloy and observed the current efficiencies (approximately $52 \%$ ) were independent of the $\mathrm{Fe}^{+2}$ concentration in chloride baths, but decreased to a level of about $18 \%$ in sulfate baths.

To study the influence of the current density on the structure of the electrodeposited $\mathrm{CoFeV}$, we carried out XRD measurements as shown in Figs. 2(a), (b), and (c) for current densities $3 \mathrm{~mA} / \mathrm{cm}^{2}, 10 \mathrm{~mA} / \mathrm{cm}^{2}$, and $50 \mathrm{~mA} /$ $\mathrm{cm}^{2}$, respectively. All XRD patterns have sharp peaks, which means all samples were crystallized. The presence of bcc (200) and bcc (211) peaks means our samples were alloys. Similar results were observed for electrodeposited CoFe alloy [13]. From the XRD patterns, we know that all the peaks of the $\mathrm{CoFeV}$ films are consistent with those of a typical Co hcp and Fe bcc mixed phase. An increase in the current density yielded a decreased sharpness of the major peaks, as shown in Fig. 2, a decrease in the grain size of our samples. Also, the peak position shift to lower angle means the lattice constant increased with increasing current density. For an electrodeposited $\mathrm{Cu}_{90} \mathrm{Co}_{10}$ thin film, Lopez et al. [9] found in as-deposited and annealed samples a mixed $\mathrm{Cu}-\mathrm{Co}$ fcc phase with peaks close to those of the $\mathrm{Cu}$ fcc peaks. No peaks of the Co fcc or the Co hcp phase were found in any sample. In a study of deposited CoFe alloys, Kim et al. [13] observed a mixed hcp and bcc phase. They showed that the anion types did not affect the phases of the deposited CoFe, but influenced the magnetic properties.

Figure 3 shows the variation of the saturation magnetization $\left(M_{S}\right)$ of electrodeposited $\mathrm{CoFeV}$. The saturation magnetization increased from about 2.2 to $2.5 \mathrm{~T}$ with 


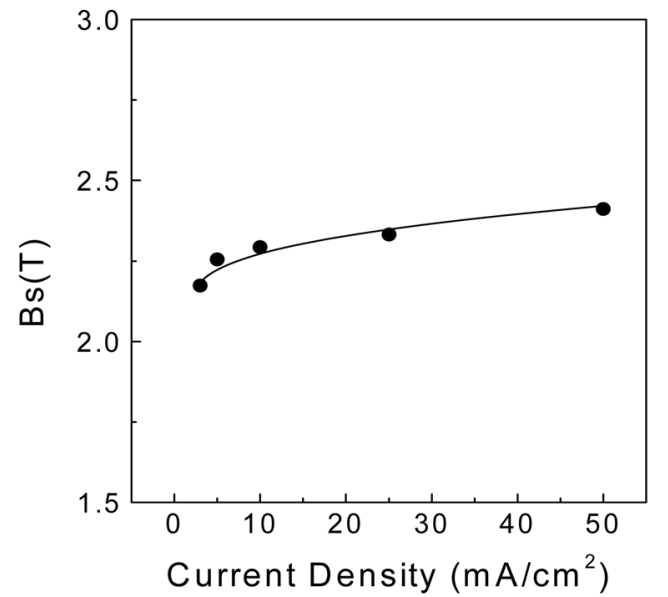

Fig. 3. Magnetic saturation variation of $\mathrm{CoFeV}$ films with current density.

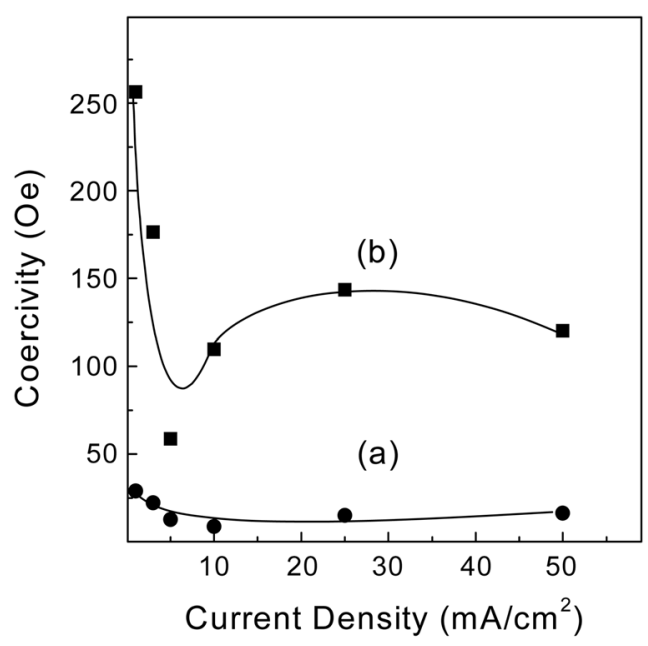

Fig. 4. Coercivity variation of $\mathrm{CoFeV}$ films with current density measured in the (a) in-plane and (b) perpendicular directions.

increasing current density. The saturation magnetization of electrodeposited $\mathrm{CoFeV}$ increased with increasing deposit Co contents, as shown in Fig. 1. The observed saturation magnetization variation is reasonable from the fact that the saturation magnetization is an intrinsic magnetic property, which depends only on the film composition. In a study of deposited CoFe alloys Kim et al. [13] observed that the saturation magnetization of electrodeposited $\mathrm{CoFe}$ was independent of the anion type and increased with increasing $\mathrm{Fe}$ content. It is known that the Fe-Co alloys have large saturation magnetizations; the maximum occurs in a $50 \mathrm{Co}-50 \mathrm{Fe}$ alloy (Permendur). The addition $2 \%$ vanadium reduces the coercive force and the hysteresis losses and increases the electrical resistivity and ductility [14].

Figure 4 shows the variation of the coercivity $\left(H_{C}\right)$. The coercivity measured in the perpendicular direction decreased from 260 to 120 Oe with increasing current density; a drastic drop of 60 Oe occurred at $5 \mathrm{~mA} / \mathrm{cm}^{2}$. The coercivity measured in the in-plane direction was almost unchanged, at about $20 \mathrm{Oe}$, with increasing current density. These magnetic properties could be relate to the compositions of the films. As Fig. 1 shows, the Co contents increased with increasing current density, so the films became more strongly ferro-magnetic. In the $\mathrm{CoFe}$ alloy [13], the coercivity for a chloride bath increased from 17 (at $0 \mathrm{wt} . \% \mathrm{Fe}$ ) to $40 \mathrm{Oe}(>18 \mathrm{wt} . \% \mathrm{Fe}$ ) and then reached a plateau. In electrodeposited $\mathrm{Co}_{\mathrm{x}} \mathrm{Re}_{100-\mathrm{x}}$, Jones et al. [10] also observed that for higher Co concentrations, the films were ferromagnetic.

\section{Acknowledgements}

This work was supported by Konkuk University in 2005.

\section{References}

[1] S. S. Parkin, Appl. Phys. Lett. 60, 512 (1992).

[2] C. Petit and M. P. Pileni, J. Magn. Magn. Mater. 166, 82 (1997).

[3] J. Hong, E. Key, and S. X. Wang, IEEE Trans. Magn. 32, 4475 (1996).

[4] V. M. Fedosyuk, O. I. Kasyutich, D. Ravinder, and H. J. Blythe, J. Magn. Magn. Mater. 156, 345 (1996).

[5] R. Ropez Anton, M. L. Fdez-Gubieda, M. Insauti, A. Garcia-Arribas, and J. Herreros, J. Non-Cryst. Solids 287 (1-3), 26 (2001).

[6] C. Tsang, H. Santini, D. McCowan, J. Lo, and R. Lee, IEEE Trans. Magn. 32, 7 (1996).

[7] V. M. Fedosyuk and J. M. Riveiro, J. Non-Cryst. Solids 143, 99 (1996).

[8] J. M. D. Coey and G. Hinds, J. Alloys and Compounds 326, 238 (2001).

[9] R. Ropez Anton, M. L. Fdez-Gubieda, G. Kurlyandskaya, and A. Garcia-Arribas, J. Magn. Magn. Mater. 254, 85 (2003).

[10] G. A. Jones, C. A. Faunce, D. Ravinder, H. J. Blythe, and V. M. Fedosyuk, J. Magn. Magn. Mater. 184, 28 (1998).

[11] V. Georgescu and M. Georgescu, J. Magn. Magn. Mater. 242, 416 (2002).

[12] D. Y. Park, N. V. Myung, M. Schwartz, and K. Nove, Electrochimica Acta 47, 2893 (2002).

[13] Daheum Kim, D. Y. Park, B. Y. Yoo, P. T. A. Sumodjo, and N. V. Myung, Electrochimica Acta 48, 819 (2003).

[14] A. H. Morrish, The Physical Principle of Magnetism, The Institute of Electrical and Electronics Engineers, New York (2001) pp. 410. 